\title{
Transient kinetics of toluene interaction with V/Ti-oxides in anaerobic conditions
}

\author{
Dmitri A. Bulushev ${ }^{\mathrm{a}, *}$, Evgeny A. Ivanov ${ }^{\mathrm{b}}$, Sergei I. Reshetnikov ${ }^{\mathrm{b}}$, \\ Lioubov Kiwi-Minsker ${ }^{\mathrm{a}}$, Albert Renken ${ }^{\mathrm{a}}$ \\ ${ }^{a}$ Swiss Federal Institute of Technology, LGRC-EPFL, CH-1015 Lausanne, Switzerland \\ ${ }^{\mathrm{b}}$ Boreskov Institute of Catalysis, 630090 Novosibirsk, Russia
}

\begin{abstract}
Toluene interaction with the catalysts consisting of $0.35,0.62,0.75$ and 3.7 monolayers (ML) of $\mathrm{VO}_{x}$ supported on anatase-titania, containing potassium, was studied by transient response techniques at 523-673 K. FT-Raman spectroscopy under dehydrated conditions was used to determine the state of vanadia. K-perturbed $\left(1020 \mathrm{~cm}^{-1}\right)$ and $\mathrm{K}$-doped $\left(990 \mathrm{~cm}^{-1}\right)$ monomeric vanadia species as well as "amorphous" $\mathrm{KVO}_{3}$ (960-940 $\left.\mathrm{cm}^{-1}\right)$ were found at vanadia coverage less than a monolayer. Bulk $\mathrm{V}_{2} \mathrm{O}_{5}\left(994 \mathrm{~cm}^{-1}\right)$ was present only in the $3.7 \mathrm{ML} \mathrm{V} / \mathrm{TiO}{ }_{2}$ catalyst as a dominant species. Benzaldehyde (BA), total oxidation products and surface carbon-containing species were the main products of the toluene interaction. The proposed reaction network involves five steps and two types of oxygen sites. $\mathrm{Both}$ the $\mathrm{BA}$ and $\mathrm{CO}_{2}$ formation increased with the concentration of vanadia. The former is determined mainly by nucleophilic-lattice oxygen that is involved in the monolayer vanadia species. The latter as well as the formation of the main part of surface carbon-containing species increased much more steeply being dependent, probably, from electrophilic oxygen abundant in polymerised vanadia species and $\mathrm{V}_{2} \mathrm{O}_{5}$. The performed kinetic modelling satisfactorily describes the response curves of $\mathrm{BA}, \mathrm{CO}_{2}$ and toluene obtained during the toluene interaction with the pre-oxidised $0.35-0.75$

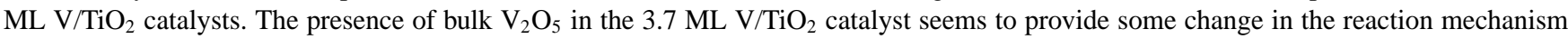
demanding a modification of the reaction scheme.
\end{abstract}

(C) 2004 Elsevier B.V. All rights reserved.

Keywords: Vanadia/titania catalyst; Toluene partial oxidation; Transient response technique; Kinetic modelling; FT-Raman spectroscopy; Periodic operation

\section{Introduction}

Cyclic reduction and re-oxidation of the catalyst is one of the ways to reach an improved performance in catalytic partial oxidation reactions. This operation is industrially used in the DuPont process of butane oxidation to maleic anhydride over a vanadium-phosphorous catalyst [1]. The reason to apply this cycle was to improve the selectivity by a decrease of the concentration of surface electrophilic oxygen, which is thought to be responsible for total oxidation. The common objectives of the use of periodic operation in catalytic reactors are to provide an increased conversion, selectivity and reduced deactivation [2]. Important mechanistic information could be extracted from the transient behaviour of the

\footnotetext{
* Corresponding author. Tel.: +4121693 31 86; fax: +41216936091.

E-mail address: dimitri.boulouchev@epfl.ch (D.A. Bulushev).
}

reaction after a fast change of the composition of reaction mixture over the catalyst. Modelling of the transient phenomena allows obtaining valuable kinetic constants, which often could not be determined from the steady-state experiments.

Mills et al. [3] using the TAP reactor investigated the details of the reduction kinetics of the vanadium-phosphorous catalyst by butane and its re-oxidation by oxygen. An interaction of the components of the reaction mixture with V/Ti-oxide catalysts was intensively studied for $o$-xylene oxidation [4-6] - important industrial reaction of phthalic anhydride production. This has been done also for toluene oxidation [5,7-9]. In our study [8,9], during toluene interaction with a V/Ti-oxide catalyst containing potassium it was found that benzaldehyde (BA) is formed for a long time with a very high selectivity while $\mathrm{CO}_{2}$ is evolved only during the first moments of the reaction. This was assigned to different surface oxygen species: nucleophilic and electrophilic 


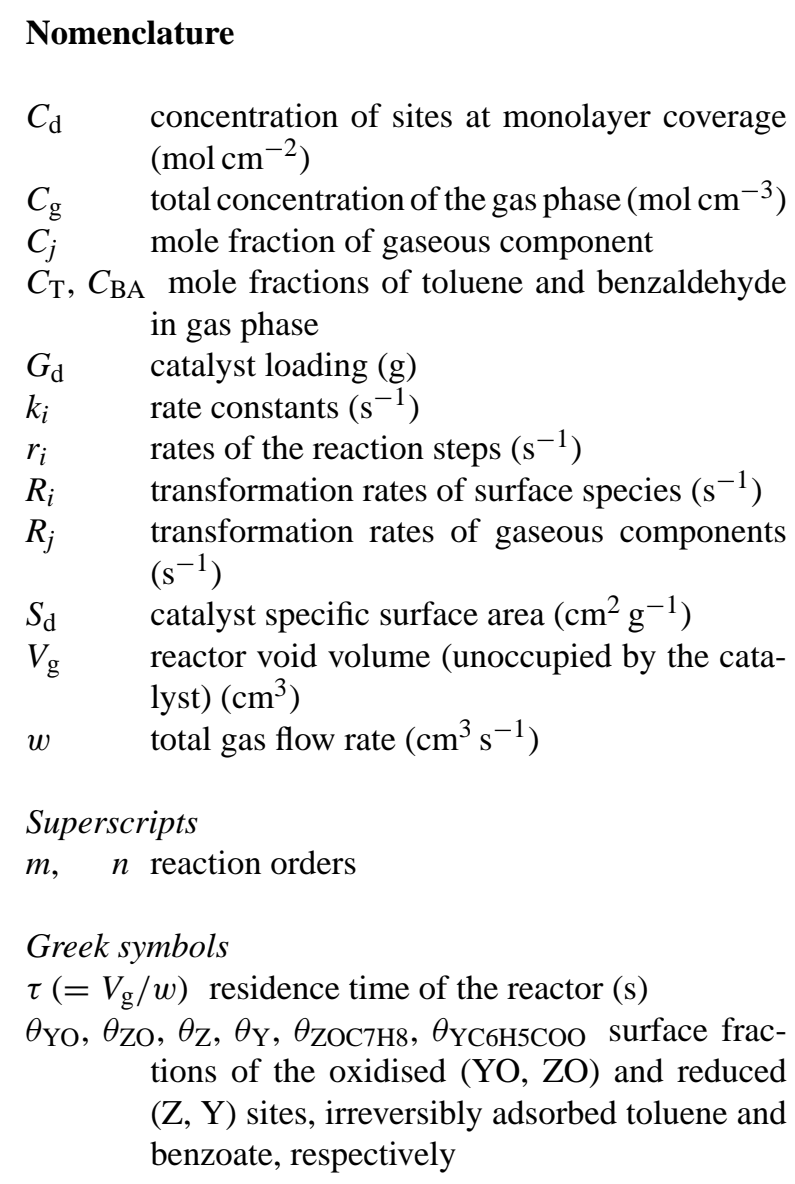

\section{Superscripts}

$m, \quad n$ reaction orders

\section{Greek symbols}

$\tau\left(=V_{\mathrm{g}} / w\right)$ residence time of the reactor (s)

$\theta_{\mathrm{YO}}, \theta_{\mathrm{ZO}}, \theta_{\mathrm{Z}}, \theta_{\mathrm{Y}}, \theta_{\mathrm{ZOC} 7 \mathrm{H} 8}, \theta_{\mathrm{YC} 6 \mathrm{H} 5 \mathrm{COO}}$ surface fractions of the oxidised $(\mathrm{YO}, \mathrm{ZO})$ and reduced $(\mathrm{Z}, \mathrm{Y})$ sites, irreversibly adsorbed toluene and benzoate, respectively

species participating in the parallel routes of the toluene oxidation.

Steady-state kinetics of the toluene oxidation and deactivation of the pure V/Ti-oxide were also studied [10]. Low yields of the BA formation even at low conversions of toluene $(2-10 \%)$ in the presence of oxygen are explained by a high rate constant of the BA transformation into benzoic acid. Oxygen-18 experiments allowed Konietzni et al. [7] to conclude that the toluene oxidation in the presence of oxygen proceeds over the microporous vanadia/silica catalyst and $\mathrm{V}_{2} \mathrm{O}_{5}$ via a Mars-van Krevelen mechanism by insertion of lattice oxygen into the products. The same mechanism could be expected for the V/Ti-oxide catalyst.

The main objective of the present work is to deepen the knowledge concerning the mechanism of toluene oxidation over V/Ti-oxide catalysts by studying the reaction in anaerobic conditions using transient response techniques in combination with kinetic modelling. The effect of vanadium concentration on the toluene interaction with oxidised catalysts was considered in detail especially in the range of sub-monolayer quantities. Important is that the catalysts contained potassium initially present in titania support. The reason to study these samples instead of undoped ones was that during toluene interaction with the latter gaseous products were almost not observed, because of strong adsorption on the surface [11]. The catalysts were extensively characterised by FT-Raman spectroscopy, TPR, XPS, HRTEM [12] and ${ }^{51} \mathrm{~V}$ NMR [9]. However, until now these methods may not be used for quantitative determination of the concentration of active sites responsible for partial and total oxidation. Hence, kinetic modelling was applied in the present study as a tool for estimation of their relative concentrations.

\section{Experimental}

\subsection{Catalyst preparation}

$\mathrm{TiO}_{2}$ (Aldrich) with the anatase structure was used as a support. It contained $0.2 \mathrm{wt} . \%$ of potassium as was determined by inductively coupled plasma spectrometry (ICP, Baird). Sub-monolayer catalysts with $0.27,0.47$ and 0.57 wt. \% V-content were prepared by 2-, 5- and 10-steps of $\mathrm{VOCl}_{3}$ vapour deposition on the surface of $\mathrm{TiO}_{2}$, respectively, hydroxylation and drying (grafting technique [13]). Impregnation from aqueous solution of vanadium oxalate was used to obtain a catalyst with $2.8 \mathrm{wt} . \%$ of V. The catalysts were dried and then calcined in air at $723 \mathrm{~K}$ during $120 \mathrm{~min}$. The BET specific surface area was equal to $9 \mathrm{~m}^{2} \mathrm{~g}^{-1}$. The amount of vanadium corresponds to $0.35,0.62,0.75$ and 3.7 $\mathrm{ML}$, respectively. The monolayer is taken as equal to $10 \mathrm{~V}$ atom $\mathrm{nm}^{-2}$ [14]. The presence of $\mathrm{K}$ was found on the surface of these catalysts by XPS [12]. It is important that $\mathrm{K}$ affects the structure of vanadia species, acid-base properties of the catalysts as well as reactivity of surface oxygen $[9,12,14,15]$.

\subsection{Set-up and procedure}

An experimental set-up used for the transient kinetics study has been described elsewhere [16]. Toluene was introduced into a heated evaporator by a syringe-pump. Products were analysed by mass spectrometry and gas chromatography. Measurements were carried out in a tubular flow reactor made of quartz $(130 \times 6 \mathrm{~mm})$. A thermocouple was inserted into the middle of the catalyst bed. All lines of the set-up were heated up to $413 \mathrm{~K}$ at least. For the transient response study the catalyst loading and the gas flow were maintained constant at $1 \mathrm{~g}$ and $1 \mathrm{~cm}^{3} \mathrm{~s}^{-1}$ at standard temperature and pressure, respectively. The nitrogen response time after the switch of Ar to a 2 vol.\% $\mathrm{N}_{2} / 98 \mathrm{vol} . \%$ Ar mixture over the catalyst was small and close to $3 \mathrm{~s}$ (Fig. 1). The response of toluene over quartz particles was very similar.

All the catalysts before the reaction were pre-treated in oxidative atmosphere $\left(20 \mathrm{vol} . \% \mathrm{O}_{2}\right.$, rest $\left.\mathrm{Ar}\right)$ at $673 \mathrm{~K}$ for $30 \mathrm{~min}$. After this pre-treatment, the reactor was cooled in $\mathrm{Ar}$, until the temperature of the reaction (523-673 K) and the flow was switched to the mixture of 2 vol.\% toluene with Ar in the absence of gaseous oxygen.

Two types of transient response techniques were used: response to a step-input and response to a pulse-input. During the step-input experiments interaction of toluene with 
pre-oxidised catalysts was performed for $20 \mathrm{~min}$. During the pulse-input experiments, the same toluene/Ar mixture contacted with the catalyst shortly for $2.5 \mathrm{~s}$ and then the flow was switched back to pure Ar until no gaseous products were observed by the mass spectrometer. This cycle was repeated several times. The total amount of toluene, which passed the catalyst during the single pulse, was small and corresponded to 0.12 molecule $\mathrm{nm}^{-2}$.

Concentration of carbon-containing species on the catalyst surface was determined after purging the reactor in $\mathrm{Ar}$ by transient and temperature-programmed oxidation (up to $683 \mathrm{~K}$ ) in oxygen. The amount of these species was found by integration of the area under the carbon oxides curves obtained in this run. Relative sensitivity factors of the mass spectrometer for these products with respect to oxygen were used to determine the concentrations.

\subsection{Catalyst characterisation}

Raman spectroscopy measurements were performed using a Perkin Elmer FT-Raman 2000 spectrometer. An "in situ" Raman spectroscopy cell [17] was attached to the same set-up mentioned above instead of the tubular reactor. An Nd-YAG laser, operating at $1064 \mathrm{~nm}$ with a varying power in the range of $10-750 \mathrm{~mW}$ was used in the FT-Raman spectrometer. From 32 to 256 scans were averaged with a resolution of $4 \mathrm{~cm}^{-1}$ to obtain a spectrum. The spectra of the catalysts were taken in the dry $\mathrm{O}_{2} / \mathrm{Ar}$ mixture at $523 \mathrm{~K}$ after the pre-treatment in this mixture at $673 \mathrm{~K}$ for $30 \mathrm{~min}$ implying dehydrated conditions.

\section{Results and discussion}

\subsection{Interaction of toluene with the $0.75 \mathrm{ML}$ V/TiO 2 catalyst}

Fig. 1 demonstrates a typical toluene interaction with the $0.75 \mathrm{ML} \mathrm{V/Ti-oxide} \mathrm{catalyst.} \mathrm{This} \mathrm{catalyst} \mathrm{was} \mathrm{mainly}$

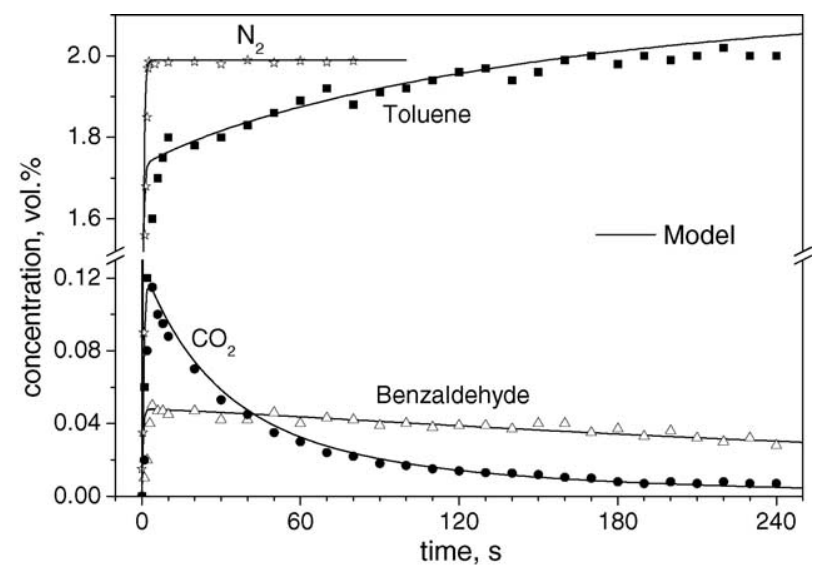

Fig. 1. Formation of products during the step-input of toluene (2.05 vol.\% toluene in $\mathrm{Ar}$ ) on the pre-oxidised $0.75 \mathrm{ML} \mathrm{V} / \mathrm{TiO}_{2}$ catalyst at $603 \mathrm{~K} . \mathrm{N}_{2}$ response obtained during the step-input of a 2 vol.\% $\mathrm{N}_{2} / \mathrm{Ar}$ mixture on the catalyst is shown for comparison (everywhere points - experiments, lines modelling). studied because it contained vanadia only in the form of surface monolayer vanadia species and no bulk crystalline $\mathrm{V}_{2} \mathrm{O}_{5}$ [12]. However, the vanadia concentration in this sample was close to the monolayer coverage implying a decrease of the possible contribution of uncovered titania sites to the reaction.

It is seen that the dynamics of the $\mathrm{CO}_{2}$ and $\mathrm{BA}$ formation are different. $\mathrm{CO}_{2}$ is formed during the initial time of the reaction declining quickly in time, while BA is formed for a prolonged time. This was explained earlier by participation of different oxygen species in partial and total oxidation [8]. Initial shape of the BA curve is similar to that of the toluene curve pointing out direct dependence on the toluene partial pressure. After some time in the toluene/Ar stream the BA concentration decreases with the decrease of the concentration of active surface oxygen. Small amount of CO (5-6 times less than $\mathrm{CO}_{2}$ ) was also observed in products with the transient behaviour similar to $\mathrm{CO}_{2}$.

Valuable information concerning the $\mathrm{BA}, \mathrm{CO}_{2}$ formation and toluene adsorption follows from the pulse-input experiments (Fig. 2). These experiments could be considered as a titration of the catalyst oxygen by toluene. The toluene curve reaches a maximum and then decreases due to the switch to $\mathrm{Ar}$ flow. The toluene step-down response is always close to the one over inert quartz instead of the catalyst showing that reversible adsorption of toluene is negligible. This is in accordance with the data in the presence of gaseous oxygen $[10,16]$. An increase of toluene amount from pulse to pulse indicates a decrease of toluene conversion. This takes place because of surface oxygen consumption and blocking of active sites by surface carbon-containing species formed in the reaction.

The BA curves are very similar in a sequence of runs (Fig. 2). This points out that a single interaction with toluene does not change noticeably the concentration of oxygen species, which are responsible for the BA formation. This confirms that these oxygen species are in large excess in accordance with the continuous run (Fig. 1). However, the total

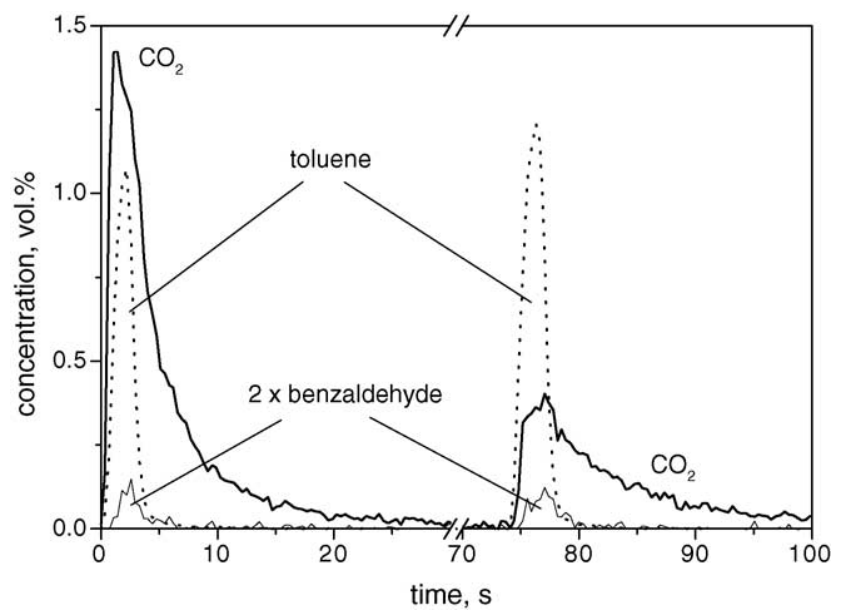

Fig. 2. Formation of products during the pulse-input of toluene on the preoxidised $0.75 \mathrm{ML} \mathrm{V} / \mathrm{TiO}_{2}$ catalyst at $673 \mathrm{~K}$. 
amount of oxygen involved in the BA formation in the experiment like that presented in Fig. 1 during $500 \mathrm{~s}$ at any studied temperature consists of only small fraction from a monolayer coverage $(<0.1)$ indicating that only surface oxygen and no oxygen from the bulk of titania participates.

The $\mathrm{CO}_{2}$ behaviour is very different (Fig. 2). When toluene is removed from the reactor, $\mathrm{CO}_{2}$ is still produced for some time $(50 \mathrm{~s})$, being formed in a reaction of surface carboncontaining species with oxygen of the catalyst. The formation of $\mathrm{CO}_{2}$ is accompanied by the water vapour formation (not shown). The re-adsorption of $\mathrm{CO}_{2}$ may not contribute at the studied temperature range. The consecutive toluene pulses show that the reactive oxygen is present on the catalyst surface as $\mathrm{CO}_{2}$ is formed. However, contrary to the behaviour of BA, the amount of $\mathrm{CO}_{2}$ strongly decreases in a sequence of pulses (Fig. 2) indicating a strong decrease of the reactive oxygen concentration.

Except the formation of gaseous products, the formation of some carbon-containing species takes place on the catalyst surface. It follows from the carbon balance measurements as well as from the transient oxidation of the catalyst after its interaction with toluene (Fig. 3). $\mathrm{CO}_{2}, \mathrm{CO}, \mathrm{H}_{2} \mathrm{O}$ (not shown), but no BA, benzoic acid and maleic anhydride were found during oxidation of this catalyst at $603 \mathrm{~K}$. Consecutive heating of the sample in oxygen up to $683 \mathrm{~K}$ did not provide any additional product formation indicating that all surface carbon-containing species can be removed in oxygen at $603 \mathrm{~K}$. The total surface concentration of these species determined by oxidation corresponds to $2.5 \mathrm{C}$-atom $\mathrm{nm}^{-2}$. Different benzoates were observed earlier during the toluene interaction with vanadia/titania catalysts by FTIR spectroscopy $[18,19]$. Coke-like species with a decreased H/C ratio with respect to toluene may be also formed $[10,16,20]$.

\subsection{Structure of vanadia species}

The Raman spectra of the oxidised catalysts measured under dehydrated conditions are shown in Fig. 4. As it was mentioned the titania used as a support contained potassium,

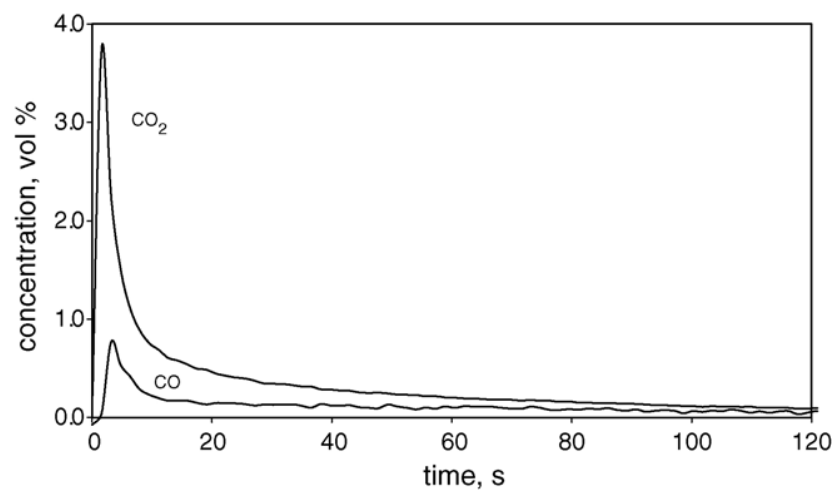

Fig. 3. Formation of products during the step-input of a 20 vol. $\% \mathrm{O}_{2} / \mathrm{Ar}$ mixture on the $0.75 \mathrm{ML} \mathrm{V/TiO} 2$ catalyst at $603 \mathrm{~K}$ after $20 \mathrm{~min}$ of the toluene interaction (Fig. 1) and Ar purge.
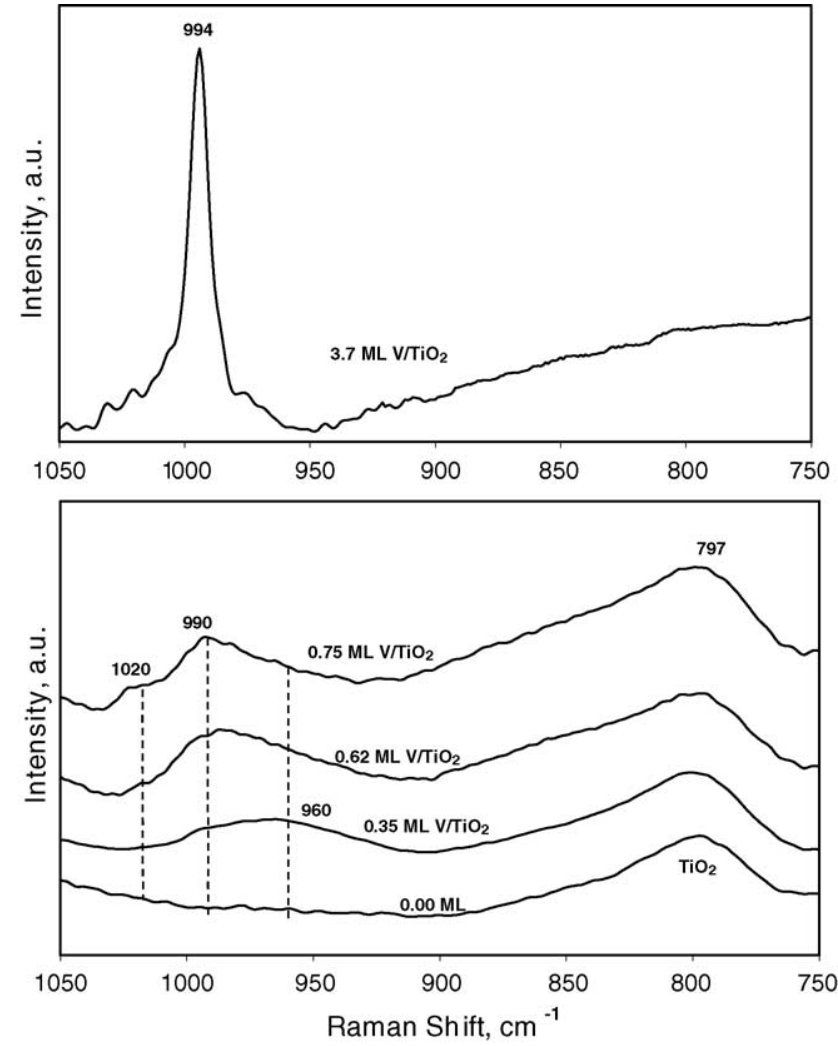

Fig. 4. FT-Raman spectra of the $\mathrm{V} / \mathrm{TiO}_{2}$ catalysts and $\mathrm{TiO}_{2}$ measured in the $20 \mathrm{vol} . \% \mathrm{O}_{2} / \mathrm{Ar}$ mixture at $523 \mathrm{~K}$ under dehydrated conditions.

which was not removed after vanadia deposition. XPS analysis showed that the $\mathrm{K} / \mathrm{V}$ surface atomic ratio in the $0.35,0.62$ and $0.75 \mathrm{ML} \mathrm{V} / \mathrm{TiO}_{2}$ catalysts corresponded to $1,0.57$ and 0.47 , respectively [12].

The presence of K-impurities provided the difference in the Raman spectra of the catalysts with respect to the ones obtained for the pure V/Ti-oxides [17,21]. For the sub-monolayer catalysts the following bands are present: $1020,980-1000$ and $940-960 \mathrm{~cm}^{-1}$. They are assigned to the K-perturbed, K-doped monomeric vanadia species and bulk "amorphous" $\mathrm{KVO}_{3}$, respectively, basing on the FTRaman and TPR study of the catalysts intentionally doped by potassium $[12,15]$. Vanadium in all of these species is tetra-coordinated. Contrary to the sub-monolayer catalysts the $3.7 \mathrm{ML} \mathrm{V} / \mathrm{TiO}_{2}$ catalyst contained bulk $\mathrm{V}_{2} \mathrm{O}_{5}$ as a dominant species, which is characterised by a very intensive and narrow band at $994 \mathrm{~cm}^{-1}$ (Fig. 4). The monolayer vanadia species in this catalyst must exist also, but are not clearly seen in the spectra, because of the strong $\mathrm{V}_{2} \mathrm{O}_{5}$ band. The presence of bulk crystalline vanadia $\left(\mathrm{V}_{2} \mathrm{O}_{5}\right)$ in this catalyst was also confirmed by HRTEM and ${ }^{51} \mathrm{~V}$ NMR spectroscopy [9].

An important fact is that the FT-Raman study shows that different vanadia (oxygen) species exist on the surface of the studied catalysts. The shape of the $\mathrm{V}=\mathrm{O}$ bands region (900-1050 $\mathrm{cm}^{-1}$, Fig. 4) is dependent on the concentration of vanadia and indicates that the ratio of different vanadia 

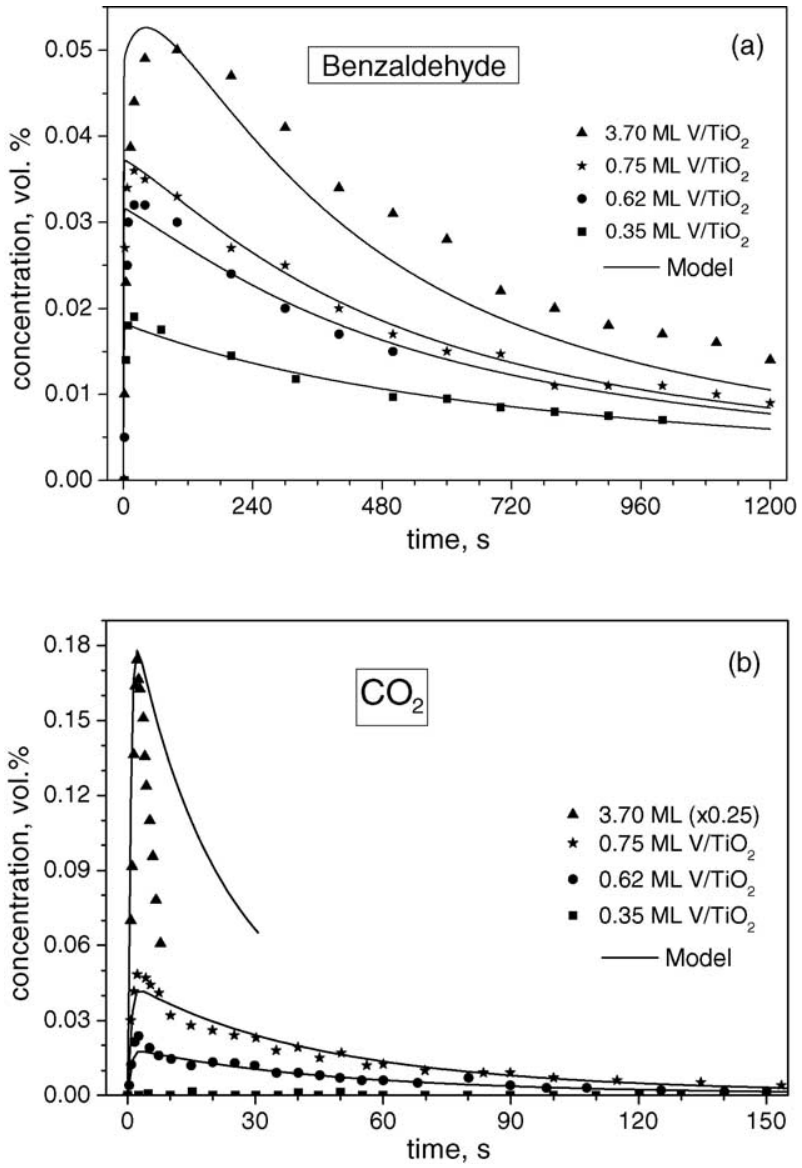

Fig. 5. Dependences of the benzaldehyde (a) and $\mathrm{CO}_{2}$ (b) formation on time during the step-input of a $2 \mathrm{vol} \% \%$ toluene/Ar mixture on the pre-oxidised V/Ti oxide catalysts at $573 \mathrm{~K}$ (points - experiments, lines - modelling).

species changes. This fact will be used for kinetic modelling of the toluene interaction with these catalysts.

\subsection{Effect of the vanadia coverage on the toluene interaction}

The $\mathrm{BA}$ and $\mathrm{CO}_{2}$ formation in transient conditions are compared during the toluene interaction with the pre-oxidised catalysts containing different vanadia concentrations (from 0.35 to $3.7 \mathrm{ML}$ ) at the same temperature (573 K) (Fig. 5). No gaseous products were detected during the interaction of toluene with the titania support. Small amount of benzoic acid was found only for the $3.7 \mathrm{ML} \mathrm{V/TiO}{ }_{2}$ catalyst at higher temperatures. Maleic anhydride has never been observed during the toluene interaction.

For all the sub-monolayer catalysts, the ratio of the amount of oxygen atoms removed from the catalyst in the form of gaseous products (including water) to the amount of vanadium atoms in the sample at $523-673 \mathrm{~K}$ was lower than 0.6 during the first $500 \mathrm{~s}$ of the interaction. Hence it was concluded that bulk-surface oxygen diffusion processes do not contribute to the reduction of these catalysts. For the 3.7 ML $\mathrm{V} / \mathrm{TiO}_{2}$ catalyst this ratio was not higher, however if to relate the amount of the removed oxygen to the amount of the vanadium in the monolayer $\left(10 \mathrm{~V}\right.$-atom $\left.\mathrm{nm}^{-2}\right)$ the ratios reached 1.2 and 1.7 at 633 and $673 \mathrm{~K}$, respectively. These high values indicate that oxygen of the bulk $\mathrm{V}_{2} \mathrm{O}_{5}$ is involved in the toluene interaction with this catalyst.

The BA formation is observed at the coverage by vanadia as low as $0.35 \mathrm{ML}$ and increases with the vanadia content (Fig. 5a). Strong increase of the vanadia content from 0.75 to 3.7 ML results in only a small increase of the BA formation. These data point out that the monolayer vanadia species are mainly active in the $\mathrm{BA}$ formation and bulk $\mathrm{V}_{2} \mathrm{O}_{5}$ possesses a lower activity.

Carbon dioxide is not observed on the catalyst with the lowest concentration of vanadia (0.35 ML) (Fig. 5b). Formation of $\mathrm{CO}_{2}$ is not directly proportional to the vanadia coverage being strongly increased for the catalyst containing bulk $\mathrm{V}_{2} \mathrm{O}_{5}$ particles (3.7 ML). Another type of oxygen, probably, electrophilic mainly abundant on the surface of the bulk $\mathrm{V}_{2} \mathrm{O}_{5}$ seems to participate in the $\mathrm{CO}_{2}$ formation. The absence of this type of oxygen results in $100 \%$ BA selectivity for the $0.35 \mathrm{ML} \mathrm{V} / \mathrm{TiO}_{2}$ catalyst.

A total concentration of the surface carbon-containing species determined by oxidation after $20 \mathrm{~min}$ of the toluene interaction increases with the vanadia content, but as well as the $\mathrm{CO}_{2}$ formation is not directly proportional to it (Fig. 6). It only slightly increases until $0.35 \mathrm{ML}$ of $\mathrm{V}$ and then increases drastically with the increase of the $\mathrm{VO}_{x}$ concentration reach-

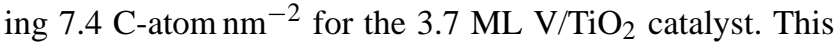
increase is, probably, provided by the appearance of electrophilic oxygen sites associated with polymerised vanadia species. At low coverage, vanadia species interact mainly with titania surface, while at high they interact each other forming polymerised vanadia and $\mathrm{V}_{2} \mathrm{O}_{5}$.

A formation of the $\mathrm{CO}_{x}$ products increases strongly with the temperature, while the concentration of the surface

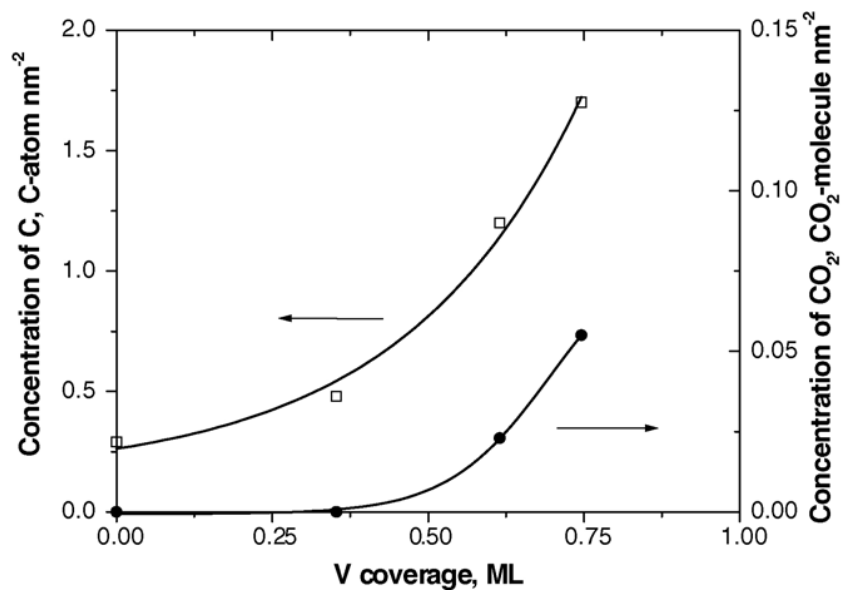

Fig. 6. Total amounts of $\mathrm{CO}_{2}$ and surface carbon-containing species formed during $20 \mathrm{~min}$ of the toluene interaction with the pre-oxidised V/Ti oxide catalysts at $573 \mathrm{~K}$ on the vanadia coverage (concentration of surface carboncontaining species is determined by temperature-programmed oxidation after the toluene interaction). 
carbon-containing species is almost independent on it in the range $573-673 \mathrm{~K}$. It corresponds to $1.7-2.5 \mathrm{C}$-atom $\mathrm{nm}^{-2}$ for the $0.75 \mathrm{ML} \mathrm{V} / \mathrm{TiO}_{2}$ catalyst and 7.4-9.5 C-atom $\mathrm{nm}^{-2}$ for the $3.7 \mathrm{ML} \mathrm{V} / \mathrm{TiO}_{2}$ catalyst. This may indicate that the coverage by surface carbon-containing species is close to saturation value after $20 \mathrm{~min}$ in the toluene stream at any studied temperature. An increase of the temperature is favourable for the aromatic ring fission and formation of carbon oxides. Surface carbon-containing species were also found to be formed on the $0.75 \mathrm{ML} \mathrm{V} / \mathrm{TiO}_{2}$ catalyst reduced in $\mathrm{H}_{2}$ for $1 \mathrm{~h}$ at $673 \mathrm{~K}$, but their total concentration $\left(0.7 \mathrm{C}\right.$-atom nm $\left.{ }^{-2}\right)$ was much lower as compared to the oxidised catalyst $(2.1$ C-atom nm ${ }^{-2}$ ).

\subsection{Kinetic modelling of the toluene interaction with the pre-oxidised catalysts}

A simulation of the toluene interaction with the preoxidised $0.75 \mathrm{ML} \mathrm{V} / \mathrm{TiO}_{2}$ catalyst at different temperatures (Figs. 1, 5, 7) as well as with the $0.35,0.62,3.7 \mathrm{ML} \mathrm{V/TiO} 2$ catalysts at $573 \mathrm{~K}$ (Fig. 5) was performed.

The kinetic model is based on the following results and assumptions:
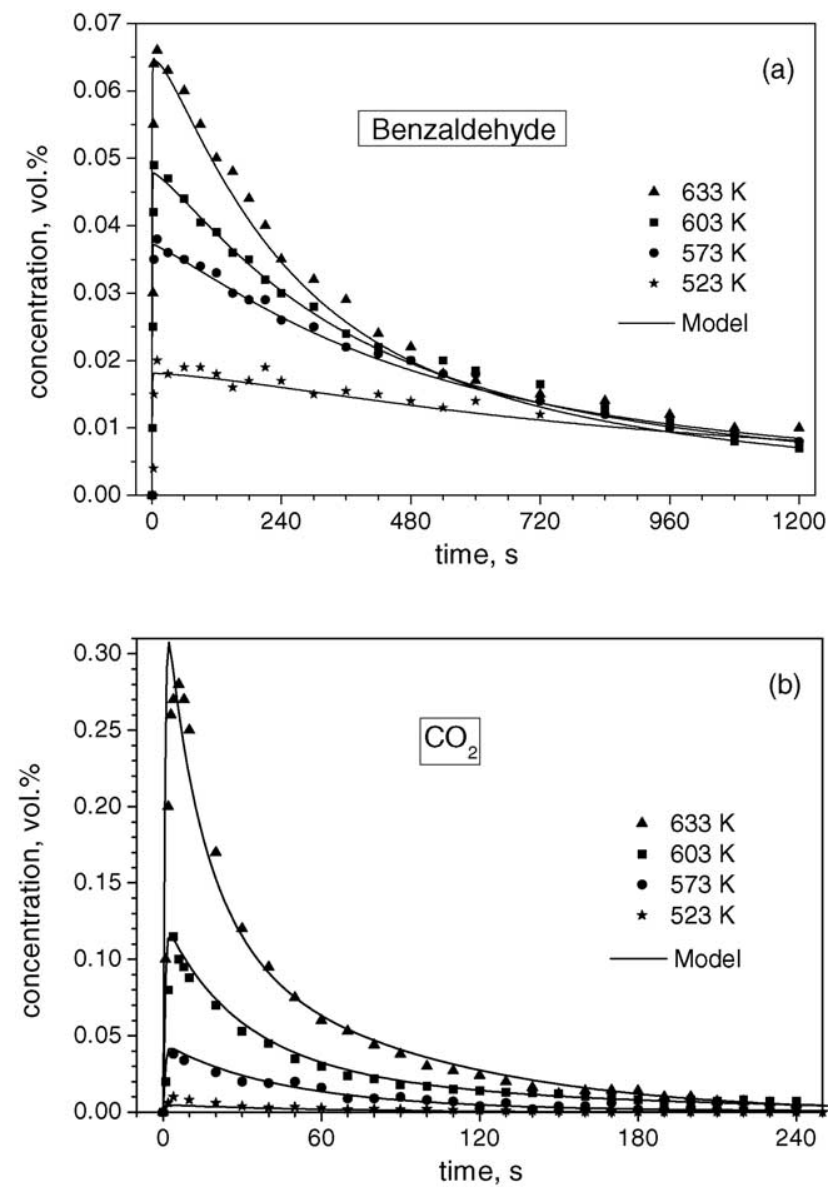

Fig. 7. Transient experimental (points) and modelling data of the BA (a) and $\mathrm{CO}_{2}$ (b) formation obtained during the step-input of toluene (2 vol.\%) on the pre-oxidised $0.75 \mathrm{ML} \mathrm{V} / \mathrm{Ti}$-oxide catalyst at different temperatures.
(1) Two different oxygen sites nucleophilic and electrophilic are responsible for the $\mathrm{BA}$ and $\mathrm{CO}_{2}$ formation, respectively [22]. The presence of potassium impurities in the catalysts strongly complicates the assignment of the reactivity to certain vanadia species. Hence the oxygen sites were arbitrary denoted as YO (nucleophilic) and ZO (electrophilic).

(2) The total amount of reactive oxygen species was accepted to be equal to the vanadium concentration for the submonolayer catalysts and the initial YO/ZO concentration ratio independent on the temperature.

(3) Concentrations of reversibly adsorbed toluene, $\mathrm{H}_{2} \mathrm{O}$, $\mathrm{CO}_{2}, \mathrm{BA}$ as well as of an intermediate of BA formation can be neglected.

(4) Adsorbed benzoates [10,18,19,23] and other carboncontaining species $[10,16,18,20]$ may be present on the surface of V/Ti-oxides in reaction conditions. Benzoates are formed in the reaction of BA with oxygen of the catalyst [18].

(5) Two processes of the $\mathrm{CO}_{2}$ formation fast and slow could exist. If toluene adsorbs with a ring parallel to the surface a strong interaction of carbon atoms with the surface takes place $[22,24]$. In the fast process toluene interacts simultaneously with several oxygen sites accompanying by ring fission. In the slow process $\mathrm{CO}_{2}$ may be formed in a surface reaction of irreversibly adsorbed toluene with oxygen of the catalyst as follows from the pulse-input experiments (Fig. 2). CO formation is small and can be neglected.

(6) Diffusion of oxygen from the bulk of titania is not important for the sub-monolayer catalysts in the studied temperature range.

There were tested about 20 different reaction schemes. One of the key points in the choice of the reaction scheme was its simplicity reached by the use of minimal amount of reasonable steps and intermediates. The proposed kinetic scheme includes five irreversible steps, which may not be considered as elementary:

$$
\begin{aligned}
& \mathrm{C}_{6} \mathrm{H}_{5} \mathrm{CH}_{3}+2 \mathrm{YO} \rightarrow 2 \mathrm{Y}+\mathrm{C}_{6} \mathrm{H}_{5} \mathrm{CHO}+\mathrm{H}_{2} \mathrm{O} \\
& 2 \mathrm{C}_{6} \mathrm{H}_{5} \mathrm{CHO}+3 \mathrm{YO} \rightarrow 2 \mathrm{YC}_{6} \mathrm{H}_{5} \mathrm{COO}+\mathrm{Y}+\mathrm{H}_{2} \mathrm{O} \\
& \mathrm{C}_{6} \mathrm{H}_{5} \mathrm{CH}_{3}+18 \mathrm{ZO} \rightarrow 18 \mathrm{Z}+7 \mathrm{CO}_{2}+4 \mathrm{H}_{2} \mathrm{O} \\
& \mathrm{C}_{6} \mathrm{H}_{5} \mathrm{CH}_{3}+\mathrm{ZO} \rightarrow \mathrm{ZOC}_{7} \mathrm{H}_{8} \\
& \mathrm{ZOC}_{7} \mathrm{H}_{8}+17 \mathrm{ZO} \rightarrow 18 \mathrm{Z}+7 \mathrm{CO}_{2}+4 \mathrm{H}_{2} \mathrm{O}
\end{aligned}
$$

The following kinetic equations for the reaction steps (1)-(5) were applied:

$$
\begin{aligned}
& r_{1}=k_{1} \mathrm{C}_{\mathrm{T}} \theta_{\mathrm{YO}}^{m}, \quad r_{2}=k_{2} C_{\mathrm{BA}} \theta_{\mathrm{YO}}, \quad r_{3}=k_{3} \mathrm{C}_{\mathrm{T}} \theta_{\mathrm{ZO}}^{n}, \\
& r_{4}=k_{4} \mathrm{C}_{\mathrm{T}} \theta_{\mathrm{ZO}}, \quad r_{5}=k_{5} \theta_{\mathrm{ZOC} 7 \mathrm{H} 8} \theta_{\mathrm{ZO}}
\end{aligned}
$$

respectively.

In the equations, $r_{i}, k_{i}$ are the rates and rate constants of the reaction steps, $C_{\mathrm{T}}, C_{\mathrm{BA}}$ are the mole fractions of toluene 
Table 1

Rate constants at $603 \mathrm{~K}$ and activation energies (with $95 \%$ confidence limits) for the reaction steps of the toluene interaction with the pre-oxidised sub-monolayer catalysts

\begin{tabular}{llllll}
\hline & $\mathrm{T} \rightarrow \mathrm{BA}(1)$ & $\mathrm{BA} \rightarrow$ benzoate $(2)$ & $\mathrm{T} \rightarrow \mathrm{CO}_{2}(3)$ & $\begin{array}{l}\mathrm{T} \rightarrow \text { irreversibly } \\
\text { adsorbed } \mathrm{T}(4)\end{array}$ & $\begin{array}{l}\text { Irreversibly adsorbed } \\
\mathrm{T} \rightarrow \mathrm{CO}_{2}(5)\end{array}$ \\
\hline$k_{i}\left(\mathrm{~s}^{-1}\right)$ & 0.07 & 0.51 & 0.91 & 0.3 & 0.0012 \\
$E_{\mathrm{a}, \mathrm{i}}(\mathrm{kJ} / \mathrm{mol})$ & $36.0+1.6$ & $6.3 \pm 0.7$ & $106.7 \pm 1.8$ & 0 & $231 \pm 7$ \\
\hline
\end{tabular}

$\mathrm{T}$ - toluene, BA - benzaldehyde.

and benzaldehyde in gas phase, $\theta_{\mathrm{YO}}, \theta_{\mathrm{ZO}}, \theta_{\mathrm{Z}}, \theta_{\mathrm{Y}}, \theta_{\mathrm{ZOC} 7 \mathrm{H} 8}$ $\theta_{\mathrm{YC} 6 \mathrm{H} 5 \mathrm{COO}}$ are surface fractions of the oxidised (YO, ZO) and reduced $(\mathrm{Z}, \mathrm{Y})$ sites, irreversibly adsorbed toluene $\left(\mathrm{ZOC}_{7} \mathrm{H}_{8}\right)$ and benzoate $\left(\mathrm{YC}_{6} \mathrm{H}_{5} \mathrm{COO}\right)$, respectively, $m$ and $n$ are the reaction orders.

The balance of active surface sites corresponds to

$\theta_{\mathrm{YO}}+\theta_{\mathrm{YC} 6 \mathrm{H} 5 \mathrm{COO}}+\theta_{\mathrm{Y}}=\theta_{\mathrm{YO}}^{0}$,

$\theta_{\mathrm{ZO}}+\theta_{\mathrm{ZOC} 7 \mathrm{H} 8}+\theta_{\mathrm{Z}}=\theta_{\mathrm{ZO}}^{0}$

where $\theta_{\mathrm{YO}}^{0}+\theta_{\mathrm{ZO}}^{0}=\theta_{\mathrm{ML}}$ is a fraction of active sites equal to the vanadia coverage (ML) for the sub-monolayer catalysts.

The first step involves an interaction of toluene with nucleophilic-lattice oxygen atoms of the catalyst (YO) taking place with the BA formation. It may include several elementary steps. The dissociative adsorption of toluene taking place with the breakage of the $\mathrm{C}-\mathrm{H}$ bond in the methyl group can be expected as rate limiting analogously to the $o$-xylene interaction [4]. This adsorption may demand two surface sites. It leads to the formation of adsorbed benzyl $\left(\mathrm{C}_{6} \mathrm{H}_{5} \mathrm{CH}_{2}-\right)[18,25]$ or benzyloxide $\left(\mathrm{C}_{6} \mathrm{H}_{5} \mathrm{CH}_{2} \mathrm{O}-\right)$ species located on one vanadium surface atom and hydroxyl group on the other. In accordance, the best description of the experimental data at different temperatures was reached with $m=2$, which indicates the necessity of two oxygen sites for this reaction. The description with $m=1$ can be reached only in a much smaller time interval. The concentration of benzyl, benzyloxide species and hydroxyl groups should be negligible in the studied conditions in accordance with the transient response data. The necessity of two oxygen sites in the first step of alkanes interaction with $\mathrm{V}_{2} \mathrm{O}_{5}$ was shown by the density functional theory calculations [26,27]. In the Step (2), $\mathrm{BA}$ reacts with the $\mathrm{YO}$ site with the benzoate $\left(\mathrm{YC}_{6} \mathrm{H}_{5} \mathrm{COO}\right)$ formation.

Electrophilic oxygen $(\mathrm{ZO})$ is responsible for the $\mathrm{CO}_{2}$ formation (Steps (3)-(5)) taking place by fission of the aromatic ring. Toluene may be adsorbed with a ring parallel to the surface on an ensemble of several $\mathrm{ZO}$ sites followed by the fast $\mathrm{CO}_{2}$ formation. In accordance, the best description is reached with $n=3$. Earlier [6], it was concluded that there are two different adsorption sites for $o$-xylene adsorption on the V/Ti-oxide surface, which include from 2 to 4 oxygen atoms. Toluene may also interact with a single $\mathrm{ZO}$ site forming irreversibly adsorbed toluene $\mathrm{ZOC}_{7} \mathrm{H}_{8}$ or coke of unclear nature (Step (4)). This irreversibly adsorbed toluene reacts slowly with another $\mathrm{ZO}$ site forming the total oxidation products (Step (5)).

The reactor was considered of continuous stirred tank type (CSTR) because the conversion of toluene was low, the residence time of the reactor was small and the modelling using this approach described satisfactorily the $\mathrm{N}_{2}$ response after the switch of Ar to a nitrogen/argon mixture (Fig. 1, $\mathrm{N}_{2}$ ). Thus, the following equations were applied:

$\frac{\mathrm{d} C_{j}}{\mathrm{~d} t}=\frac{1}{\tau}\left(C_{j}^{\mathrm{f}}-C_{j}\right)+A_{\mathrm{R}} R_{j}(C, \theta)$

$\frac{\mathrm{d} \theta_{i}}{\mathrm{~d} t}=R_{i}(C, \theta)$

$t=0, \quad C_{j}=C_{j}^{0}, \quad \theta_{i}=\theta_{i}^{0}$

where $A_{\mathrm{R}}=\frac{G_{\mathrm{d}} S_{\mathrm{d}} C_{\mathrm{d}}}{V_{\mathrm{g}} C_{\mathrm{g}}}$.

The third-order semi-implicit Runge-Kutta method for stiff equations with a step-size adjustment strategy was used to solve the system of differential nonlinear equations [28]. The consequence of the modelling steps was the following:

(1) The reactor void volume $\left(V_{\mathrm{g}}\right)$ was estimated via the $\mathrm{N}_{2}$ response simulation (Fig. 1). It was found equal to $2 \mathrm{~cm}^{3}$.

(2) For the $0.35 \mathrm{ML} \mathrm{V} / \mathrm{TiO}_{2}$ catalyst, when no $\mathrm{CO}_{2}$ formation was observed at $573 \mathrm{~K}$ (Fig. 5), it was accepted that only the YO sites with the concentration $\theta_{\mathrm{YO}}^{0}$ equal to the coverage of $\mathrm{VO}_{x}\left(\theta_{\mathrm{ML}}\right)$ are present initially. The rate constants $-k_{1}$ and $k_{2}$ (Table 1) as well as the order $m=2$ were found.

(3) At the same temperature for the $0.75 \mathrm{ML} \mathrm{V} / \mathrm{TiO}_{2}$ catalyst, with the kinetic parameters obtained in the previous modelling step the initial concentration of $\mathrm{YO}\left(\theta_{\mathrm{YO}}^{0}\right)$ was determined (Table 2). The initial concentration of $\mathrm{ZO}$ $\left(\theta_{\mathrm{ZO}}^{0}\right)$ was taken as a difference between the total cover-

Table 2

Initial coverage by active nucleophilic (YO) and electrophilic ( $\mathrm{ZO}$ ) oxygen in the pre-oxidised $\mathrm{V} / \mathrm{TiO}_{2}$ catalysts estimated by kinetic modelling

\begin{tabular}{lllll}
\hline & $0.35 \mathrm{ML} \mathrm{V} / \mathrm{TiO}_{2}$ & $0.62 \mathrm{ML} \mathrm{V} / \mathrm{TiO}_{2}$ & $0.75{\mathrm{ML} \mathrm{V} / \mathrm{TiO}_{2}}$ & $3.7 \mathrm{ML} \mathrm{V/TiO} 2$ \\
\hline$\theta_{\mathrm{YO}}^{0}$ & 0.35 & 0.51 & 0.60 & 0.98 \\
$\theta_{\mathrm{ZO}}^{0}$ & 0.00 & 0.11 & 0.15 & 0.43 \\
\hline
\end{tabular}


age of $\mathrm{VO}_{x}\left(\theta_{\mathrm{ML}}\right)$ and $\theta_{\mathrm{YO}}^{0}$. The rate constants $-k_{3}, k_{4}$, $k_{5}$ (Table 1 ) as well as the order $n=3$ were found.

(4) For the $0.62 \mathrm{ML} \mathrm{V/TiO} 2$ catalyst, $\theta_{\mathrm{YO}}^{0}$ and $\theta_{\mathrm{ZO}}^{0}$ were found by the same way as for the $0.75 \mathrm{ML} \mathrm{V} / \mathrm{TiO}_{2}$ catalyst, the same constants and reaction orders were used for calculations.

(5) For the $0.75 \mathrm{ML} \mathrm{V} / \mathrm{TiO}_{2}$ catalyst the rate constants were determined at different temperatures. The activation energies $\left(E_{\mathrm{a}, \mathrm{i}}\right)$ were found using Arrhenius plots (Table 1).

The calculated rate constants for the reaction steps at $603 \mathrm{~K}$ as well as the activation energies are presented in Table 1 . The highest rate constant corresponds to the transformation of toluene to $\mathrm{CO}_{2}$ on the $\mathrm{ZO}$ sites (Step (3)). The Step (5) has the lowest rate constant and contributes to the $\mathrm{CO}_{2}$ formation more strongly at high temperatures. The proposed model satisfactorily describes the products (Fig. 7) and toluene (Fig. 1) response curves in the temperature range $523-633 \mathrm{~K}$.

This model was used to describe the toluene interaction with four catalysts containing different amount of vanadia (Fig. 5). It follows from the Raman study (Fig. 4) that the ratio of different vanadia species changes with the vanadia content. In accordance, the kinetic modelling showed that it is not possible to simulate satisfactorily the experimental data for the different sub-monolayer catalysts keeping the same $\theta_{\mathrm{YO}}^{0} / \theta_{\mathrm{ZO}}^{0}$ ratio.

For the $3.7 \mathrm{ML} \mathrm{V} / \mathrm{TiO}_{2}$ catalyst, new bulk $\mathrm{V}_{2} \mathrm{O}_{5}$ species different from those observed for the sub-monolayer catalysts are formed in large excess (Fig. 4). For this catalyst the main part of oxygen in vanadia is not accessible by toluene, as it is located in the bulk of $\mathrm{V}_{2} \mathrm{O}_{5}$ particles. Therefore, the initial concentrations of active sites for modelling were chosen in a way to reach the maxima attained by the experimental $\mathrm{CO}_{2}$ and BA curves. The obtained initial concentrations of the active oxygen sites for that catalyst are shown in Table 2 .

With the obtained kinetic parameters (Tables 1 and 2), a good description of the kinetic data is reached for all the sub-monolayer catalysts (Fig. 5). However, the proposed reaction model demands a modification to describe the toluene interaction with the $3.7 \mathrm{ML} \mathrm{V/TiO} 2$ catalyst. It is seen, for example, that the experimental $\mathrm{CO}_{2}$ response is much narrower than the simulated one (Fig. 5). The reason is that this catalyst contains $\mathrm{V}_{2} \mathrm{O}_{5}$, which may participate in the reaction either directly or by providing of oxygen by diffusion to the monolayer vanadia sites reduced by toluene. It follows from the simulation that the total concentration of reactive oxygen for this catalyst is higher than the monolayer coverage (Table 2). In accordance, the experimental amount of oxygen removed from this catalyst exceeded the monolayer at 633 and $673 \mathrm{~K}$.

This consideration is also in line with the data obtained for the same catalysts pre-reduced in hydrogen at $673 \mathrm{~K}$. After such a treatment some formation of BA was still observed during the toluene interaction with the $3.7 \mathrm{ML}$ $\mathrm{V} / \mathrm{TiO}_{2}$ catalyst [8], but was not with the sub-monolayer catalysts. Hydrogen is known to reduce easier the monolayer species than the bulk $\mathrm{V}_{2} \mathrm{O}_{5}$ [12,21], hence some oxygen, which may not be removed from the vanadia particles in hydrogen, participates in the interaction with toluene.

\section{Conclusions}

In the vanadia/titania catalysts containing potassium, vanadia species are present in the K-perturbed, K-doped monomeric vanadia species [12], "amorphous" $\mathrm{KVO}_{3}$ and at a coverage higher than the monolayer also in the $\mathrm{V}_{2} \mathrm{O}_{5}$ form. The pre-oxidised sub-monolayer catalysts were found to be efficient in the BA formation from toluene in anaerobic conditions. The selectivity could reach up to $100 \%$.

The benzaldehyde formation is probably determined by nucleophilic-lattice oxygen, involved in the monolayer vanadia species. Electrophilic oxygen, formed at a higher concentration of vanadia, is responsible for the formation of carbon oxides and main part of surface carbon-containing species. The proposed kinetic model was used to estimate the rate constants, reaction orders, activation energies and relative amount of active oxygen sites. It satisfactorily describes the transient behaviour of benzaldehyde, $\mathrm{CO}_{2}$ and toluene for the sub-monolayer catalysts in the temperature range $523-633 \mathrm{~K}$. The model demands a modification to simulate kinetics of the toluene interaction with the $3.7 \mathrm{ML} \mathrm{V} / \mathrm{TiO}_{2}$ catalyst explained by the presence of $\mathrm{V}_{2} \mathrm{O}_{5}$ in excess. This $\mathrm{V}_{2} \mathrm{O}_{5}$ provides oxygen participating in the interaction with toluene.

\section{Acknowledgments}

The authors acknowledge the European Commission under the INCO-Copernicus Program for the financial support. The work of E.A. Ivanov and S.I. Reshetnikov was supported by RFBR (Grant No. 98-03-32395).

\section{References}

[1] R.M. Contractor, A.E. Sleight, Catal. Today 1 (1987) 587.

[2] P. Silveston, R.R. Hudgins, A. Renken, Catal. Today 25 (1995) 91.

[3] P.L. Mills, H.T. Randall, J.S. McCracken, Chem. Eng. Sci. 54 (1999) 3709.

[4] G. Creten, F.-D. Kopinke, G.F. Froment, Can. J. Chem. Eng. 75 (1997) 882

[5] Y.I. Pyatnitsky, N.I. Ilchenko, Catal. Today 32 (1996) 21.

[6] E.M. Sadovskaya, S.A. Pokrovskaya, L.G. Pinaeva, B.S. Balzhinimaev, A.A. Ivanov, React. Kinet. Catal. Lett. 48 (1992) 461.

[7] F. Konietzni, H.W. Zanthoff, W.F. Maier, J. Catal. 188 (1999) 154.

[8] D.A. Bulushev, L. Kiwi-Minsker, A. Renken, Catal. Today 61 (2000) 271.

[9] D.A. Bulushev, L. Kiwi-Minsker, V.I. Zaikovskii, O.B. Lapina, A.A. Ivanov, S.I. Reshetnikov, A. Renken, Appl. Catal. A 202 (2000) 243.

[10] D.A. Bulushev, S.I. Reshetnikov, L. Kiwi-Minsker, A. Renken, Appl. Catal. A 220 (2001) 31.

[11] F. Rainone, D.A. Bulushev, L. Kiwi-Minsker, A. Renken, Phys. Chem. Chem. Phys. 5 (2003) 4445. 
[12] D.A. Bulushev, F. Rainone, L. Kiwi-Minsker, A. Renken, Langmuir 17 (2001) 5276.

[13] G.C. Bond, Appl. Catal. A 157 (1997) 91.

[14] B. Grzybowska-Swierkosz, Appl. Catal. A 157 (1997) 263.

[15] L. Kiwi-Minsker, D.A. Bulushev, F. Rainone, A. Renken, J. Mol. Catal. A 184 (2002) 223.

[16] D.A. Bulushev, L. Kiwi-Minsker, A. Renken, Catal. Today 57 (2000) 231.

[17] D.A. Bulushev, L. Kiwi-Minsker, V.I. Zaikovskii, A. Renken, J. Catal. 193 (2000) 145.

[18] G. Busca, F. Cavani, F. Trifiro, J. Catal. 106 (1987) 471.

[19] A.J. Hengstum, J. Pranger, S.M. Hengstum-Nijhuis, J.G. Ommen, P.J. Gellings, J. Catal. 101 (1986) 323.

[20] S. Besselmann, C. Freitag, O. Hinrichsen, M. Muhler, Phys. Chem. Chem. Phys. 3 (2001) 4633.
[21] D.A. Bulushev, L. Kiwi-Minsker, F. Rainone, A. Renken, J. Catal. 205 (2002) 115.

[22] A. Bielanski, J. Haber, Oxygen in Catalysis, Marcel Dekker, New York, 1991.

[23] M. Sanati, A. Andersson, J. Mol. Catal. 81 (1993) 51.

[24] M. Witko, K. Hermann, R. Tokarz, Catal. Today 50 (1999) 553.

[25] G. Busca, J. Chem. Soc., Faraday Trans. 89 (1993) 753.

[26] F. Gilardoni, A.T. Bell, A. Chakraborty, P. Boulet, J. Phys. Chem. B 104 (2000) 12250.

[27] E. Broclawik, J. Haber, W. Piskorz, Chem. Phys. Lett. 333 (2001) 332.

[28] J. Villadsen, M.L. Michelsen, Solution of Differential Equation Models by Polynomial Approximation, Prentice-Hall, Englewood Cliffs, NJ, 1978. 